\title{
The Implementation of Self-Ordering Kiosks (SOKs): Investigating the Challenges in Fast Food Restaurants
}

Farah Adibah Che Ishak, Nurul Amjaad Che Lah, Harnidah Samengon, Siti Fatimah Mohamad \& Ainul Zakiah Abu Bakar

To Link this Article: http://dx.doi.org/10.6007/IJARBSS/v11-i10/11491

DOI:10.6007/IJARBSS/v11-i10/11491

Received: 12 August 2021, Revised: 18 September 2021, Accepted: 05 October 2021

Published Online: 26 October 2021

In-Text Citation: (Ishak et al., 2021)

To Cite this Article: Ishak, F. A. C., Lah, N. A. C., Samengon, H., Mohamad, S. F., \& Bakar, A. Z. A. (2021). The Implementation of Self-Ordering Kiosks (SOKs): Investigating the Challenges in Fast Food Restaurants. International Journal of Academic Research in Business and Social Sciences, 11(10), 1136-1150.

Copyright: (c) 2021 The Author(s)

Published by Human Resource Management Academic Research Society (www.hrmars.com)

This article is published under the Creative Commons Attribution (CC BY 4.0) license. Anyone may reproduce, distribute, translate and create derivative works of this article (for both commercial and non-commercial purposes), subject to full attribution to the original publication and authors. The full terms of this license may be seen at: http://creativecommons.org/licences/by/4.0/legalcode

Vol. 11, No. 10, 2021, Pg. 1136 - 1150

Full Terms \& Conditions of access and use can be found at http://hrmars.com/index.php/pages/detail/publication-ethics 


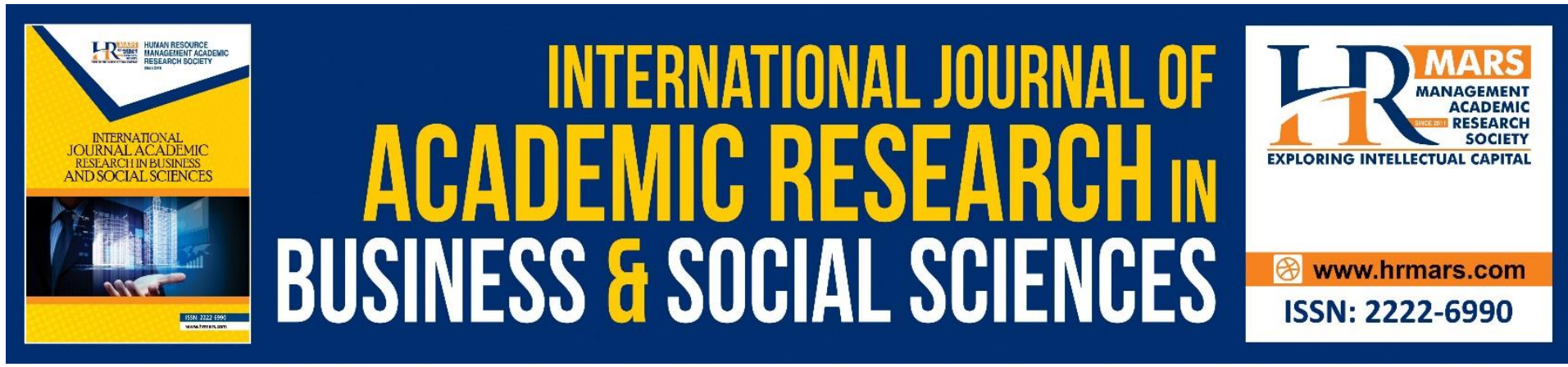

\title{
The Implementation of Self-Ordering Kiosks (SOKs): Investigating the Challenges in Fast Food Restaurants
}

\author{
Farah Adibah Che Ishak, Nurul Amjaad Che Lah, Harnidah \\ Samengon, Siti Fatimah Mohamad \& Ainul Zakiah Abu Bakar \\ Faculty of Food and Science Technology, Universiti Putra Malaysia, Malaysia \\ Email: farahadibah@upm.edu.my
}

\begin{abstract}
Placing Industry Revolution 4.0 (IR4.0) at the forefront of the digital agenda in all manufacturing industries aims to modernize industrial capability and increase competitiveness. The foodservice industry embraces this current revolution, where digital dining offers mesmerizing experiences by making the trip to restaurants more appealing and interactive. However, it is questionable if Malaysia is ready to adapt or adopt IR4.0 technologies as issues pertaining to equipment, facilities, services, and employees appear as challenges. Thus, this study explores the internal issues and identifies external challenges the QSR restaurants' managerial team faces in implementing the self-ordering kiosk (SOKs). This qualitative research obtained the data from interview sessions with informants from the management team (managers and crews) of QSR restaurants applying SOKs at their places. The interviews were transcribed verbatim and analyzed using thematic analysis. Findings showed that among the internal issues in implementing the SOKs are the insufficient number of employees and limited restaurant space. The customer acceptances, technology restrictions, and the need for regular updates are within the restaurants' external challenges in executing this innovation. In conclusion, the findings of this research can facilitate existing restaurants in managing the technology applied and, at the same time, improve their service in offering a digital dining experience to millennial customers.
\end{abstract}

Keywords: Digital Dining, Ir 4.0, Self-Ordering Kiosks, Quick-Service Restaurants, Managerial Team, Digital Dining, Technology Restriction

\section{Introduction}

The world has undergone a technological revolution that transforms the way people live and work. Some view these reforms as the beginning of a new era of change in growth and opportunity. Fourth Industrial Revolution or IR 4.0 is considered overall computerization, robotization, and smart networks (Geissbauer et al., 2016). It emerged as a promising technology to achieve efficiency, accuracy, and precision by transforming products' design, manufacture, use, operations while maintaining service (Rajput \& Singh, 2018). The global market identified the adoption of Self-Service Technology (SST) in 4.0 Industrial as a critical element for cost control and customer experience enhancement (Considine \& Cormican, 
2017). SSTs are digital interfaces that enable customers to produce a service independent of direct service employee involvement. Technology-driven, including ATM, online and mobile banking, self-check-in machines at airports, beverage vending machines, and online bill payment, are among the global market for SST (Iqbal, Hassan \& Habibah, 2018).

Nowadays, the dining landscape is changing, and the foodservice industry is adopting this current revolution. The digital revolution has stirred up the restaurant industry in various ways, first with on-the-go ordering apps and digital dining technologies that enhance the dining experience (Hopper, 2018). Digital adoption was recommended to improve the restaurants' efficiency by controlling the orders' traffic flow, generating billing data, minimizing waiting times for customers, improving operational expertise, and minimizing the restaurant's error margins (Cheong, Chiew \& Yap, 2010). Technology has driven decisionmaking, emerge new trends, and provide a better customer experience and brands in the millennium market share (KPMG, 2019). As the digitalized industry thrives, Quick Service Restaurants (QSR) are highlighted as the leading foodservice establishments undergoing digital transformation. They offer digital dining experiences beyond conventional dining to sustain and gain a more significant market share (Nicola, 2019). The QSR industry is highly expert in embracing rapid change and innovation to fulfill consumer needs to improve the speed and ease of check-out in their outlets (Nicola, 2019). Thus, technology allows quickservice companies to produce food quicker and cheaper by reducing the role of employees. In QSR, digital displays and network ordering systems replace physical displays (Ravenel, Chong \& Silva, 2016). These replacements include various types of display devices such as digital signage, touch screen, PDA system, wireless LAN, and self-ordering kiosks towards enhancing the dining experience in their establishment (Cheong, Chiew, \& Yap, 2010).

Introducing the self-ordering kiosks (SOKs) in the foodservice industry provides a better financial measure, consumer loyalty, and positive employee feedback (Ottenbacher \& Gnoth, 2005). Based on the National Restaurant Association State of the Industry report 2019, it is stated that $41 \%$ of quick-service operators plan to devote more resources to tablets, iPads, tableside ordering systems, or SOKs in their outlets to improve the level of customer experiences and expectations (Kelso, 2019). Also, Tillster (2020) noted that over 65\% of its customers would be more likely to go to a restaurant providing self-service kiosks for easy and fast orders. This proves that restaurants could benefit from opportunities provided with increased choice-making capabilities offered by kiosks (Neiman, 2019).

Even so, the introduction of the SOKs can be particularly disadvantageous for management concerning the expenditure of personnel and customer training expenses (Ravenel, Chong \& Silva, 2016). If consumers do not use the service technology implemented, the management will be forced to pay more because the employees must remain operational while at the same time paying for the new technology (Ravenel, Chong \& Silva, 2016). Therefore, service managers should carefully evaluate the plan before introducing SOKs to see if the implementation meets their usage and budget (Iqbal, Hassan \& Habibah, 2018). During the service delivery process, SOKs will reduce contact between customers and employees, challenging establishing connections between customer and employee, up-selling opportunities, and branding (Ying, 2016). Besides, SOKs can be seen as restricting customer contacts and reducing service quality. Service providers will also have to adjust their customer 
relationship techniques and adapt them to the machine-customer encounter (Zolkafli et al., 2016).

Hence, the SOKs have become an interesting topic to study and worth researching to examine whether Malaysians had accepted SOKs. Studies also can be done to prove the role of SOKs in improving the customer experiences and becoming one of the selling points to attract more customers to the businesses and increase sales. It would also be interesting to see if the Malaysian's perceived SOKs as a supportive role in the QSR industry (Mexen, 2015). A list of research on SOKs has been conducted previously, but most of them were studied beyond Malaysia's context. A short list of research has been carried out in Malaysia to examine the issues and challenges in SOKs implementation in QSRs. Many research pieces on SOKs focus on other sectors such as health, hospitality, banking, and not researching the restaurant industry. The previous studies on the QSR were focusing on additional digital dining's such as the designing and implementation of PDA (Personal Digital Assistant) - based food ordering system (Prasad, Scornavacca \& Lehmann, 2005), robotic transformation (Ivanov, Webster \& Berezina, 2017) and android online ordering (Schwab, 2016). Past studies related to SOKs conducted in Malaysia focus on customer acceptance, satisfaction, loyalty, and behavioral intention. For instance, Zolkafli et al (2016) and Mexen (2015) studied the factors influencing customers' acceptance toward SOKs, and Baba et al (2020) explored the relationship between customer SOKs usage and post-purchase behavior in QSR. Limited studies have been done in discovering issues and challenges in the SOKs in QSR from a management perspective, especially in Malaysia.

Thus, considering the discussed issues above and addressing the problems, this study explores the internal issues in applying the SOKs in QSR and identifies the external challenges in persisting SOKs in QSR in the Malaysia context.

\section{Literature Review}

\section{Industrial Revolution $\mathbf{4 . 0}$ in the Restaurant Industry}

The world has witnessed rapid technological advancement that changes people's lifestyles. This transformation's pace and breadth affect many industries and countries through the variations in improvement that the advancement brings. Industrial Revolution 4.0 has the potential to achieve the accomplishment of significant improvements in product development and service innovation, and the adoption of certain technologies may generally influence the production efficiency of manufacturing processes in the industry (Kolberg, Knobloch \& Zuhlke, 2017; Rajput \& Singh, 2019). Schwab (2016) claimed that the four main effects that the Fourth Industrial Revolution has on the business are customers' expectations, the enhancement of products, the innovation collaboration, and the forms of an organization.

Along with technological advancement, restaurants have to adapt and stay competitive to enhance guests' experience and gain maximum customer loyalty. In various technologies linked to the virtual aspect of the dining experience, the movement towards higher efficiency, effectiveness, and optimization of the experience is emerging. These technological advancements also provide restaurants with the potential to exploit the experience by introducing customers to their new products, while restaurants have new revenue opportunities (Seebacher, 2017). 
Nowadays, various forms of technology are already applied to restaurant technology, as it has become an essential part of today's industry. The point-of-sale system (POS), designed with an intuitive, easy-to-understand interface to increase productivity, is the primary technology system used in these restaurant operations where employees can switch easily, and new employees can learn quickly. Touchscreen POS terminals speed up ordering so that customers can place more orders easier and generate more sales (Ramos \& Castro, 2017). Therefore, $34 \%$ of customers said that contactless or mobile payment accessibility is now essential during Covid-19 for their dining experiences in the restaurant guide, and 33\% of customers stated that pay at the table technology is essential for their dining experiences. Order and payment at the table technology allow customers to order and pay for their meals from their smartphone for convenience and security. It provides customers peace of mind and helps increase table turn times, decrease labor costs, and better understand the customer needs with valuable information (Mexen, 2015). Besides all of the above, SOKs are the most growing trend and the most critical QSR facet.

SOKs became common for several reasons. This technology helps restaurants to fulfill customer expectations with a top-notch digital experience and easy to use interfaces. SOK also allows the customer to control the ordering process, making it easier to browse the menu and change orders. A thoughtfully designed kiosk would help restaurants increase the average check size and order volume and shorten queues while assisting the team at the restaurant avoid personnel and productivity constraints (Ravenel, Chong \& Silva, 2016).

\section{Self-Ordering Kiosks (SOKs) in Quick-Service Restaurants}

Today, digital dining has become a trend and popular in the foodservice industry, especially in QSR. Digital dining can enhance the productivity and sales of a restaurant (Troxell, 2014). In the restaurant industry, SOKs are self-service devices with a wide touch screen, allowing consumers to order food, modify their menu items, and even pay their bills without engaging with the employees (Rastegar, 2018). SOKs could minimize actual waiting times, reduce labor costs, improve speed, and boost service level (Kokkinou \& Cranage, 2013). Therefore, a SOKs is required in a QSR environment that allows customers to monitor the ordering process and reduces the customer's expected time (Liebman, 2003).

QSR is also referred to as fast-food restaurants, which offer certain food items requiring minimal preparation time, table service, and quick service delivery (Parso \& Khan, 1992). Quick-service companies continually demand customer satisfaction to be optimized and maximize profit to retain and gain a competitive advantage in the current markets (Liebman, 2003). Based on the Statista Research Department (2021), the most visited QSR in Malaysia is KFC seen by $82.81 \%$, McDonald's by $81.84 \%$, Pizza Hut with $57.18 \%$, Domino's by $57.18 \%$, and followed by other QSR. Lastly, advances in technology have positively affected the quickservice food industry, where it has been used in restaurants to elevate customer engagement and experience (Wimalaratne, 2017). QSRs' is a concept used in the dining method to prepare and serve food efficiently with a minimum service level.

McDonald's is one of the QSR that already implemented the SOK's. In 2017, McDonald's Malaysia started to refurbish and renovate its outlets with digital platforms, including SOKs, as it keeps pace with current market patterns. McDonald's also introduced cashless transactions, digital menu boards, high-speed WiFi, and USB mobile charging stations 
(Nokman, 2017). Pizza Hut also had launched the first digital concept store in Sunway Pyramid in October 2017. There are three takeaway kiosks at the revamped outlet, an Augmented Reality (AR) pizza-making game on their menu, and even robot waiters. The SOKs are certainly much snappier and more efficient because they can complete the custom order by paying cash or card at the kiosk. Simultaneously, the virtual menu has an AR feature that allows customers to make their virtual pizzas while awaiting a meal (Justin, 2017). Meanwhile, the other QSR outlet competitor, KFC, is now having a very similar phase for a while. In 2019, KFC introduced SOKs at various outlets in the Klang Valley area. This enables customers to make self-service orders and payments. SOKs at KFC accept payment through e-wallets, credit cards, and debit cards. The e-wallets accepted are including Kash Wallet, Maybank QR Pay, Alipay, WeChat Pay, Boost, and TnG wallets. KFC customers can choose to receive their food from the counter or deliver it to their table after using the SOKs (Goh, 2019).

\section{Issues Related to Self-Ordering Kiosk (SOKs)}

There are various benefits gained from the implementation of SOKs. These include operational cost reductions while dramatically improving the guest experience, strengthening the restaurant brand, and building a better image with customers (Kasavana, 2008; and Hapner, 2019). However, SOKs implementation is also accompanied by some limitations and disadvantages, especially for the management or service provider, either from internal or external sources, which required consideration and weighed against the potential rewards (Mexen, 2015). As restaurants struggle to introduce technology that allows customers to get service independently, managers frequently find it harder to adopt and maintain successful SOKs than what they may seem (Bitner, Ostrom \& Meuter, 2002).

Internal issues usually encounter from the problems that arise inside of the company. In SOKs implementation, the issues are firstly related to employement. A restaurant needs trained personnel to increase its key competency and competitive advantages with the trend and reap the benefits of technology adoption (Samantha, Ganewatta \& Åmo, 2011). The organization is demanding employees with a higher level of skills in both the back and front of the house to ensure the restaurant's efficiency. Simultaneously, restaurants face staffing crisis caused by employees shortage, high turnover, and the younger generation's reluctance to join the industry. Koontz and Weilhrich (2019) highlighted that the human resources department ensures the organization adequately selects, appraising, and developing personnel to occupy the roles planned for the system correctly and effectively. However, sometimes, due to high turnover, the managements have limited time to train the staff with adequate competence and proper skill, which leads to the lower skill of employees in delivering the service to the customers (Koontz and Weilhrich, 2019).

Apart from internal issues arising from employees or management, it can also be due to the restaurant's interior space, which is relatively narrow and limited. It can bring a problem to the management since the placement of SOKs is a crucial consideration in implementing a digital dining experience in a QSR environment. SOKs are typically installed with the latest models at a very accessible position but underutilized high traffic areas. In a QSR, kiosks are placed in a position where they form lines around the kiosks and the counter. According to Appetize Technologies (2019), floor-standing models can build their own space inside any store, as long as the freestanding is an excellent choice to highlight the kiosks and allow customers to process their orders without any doubt. This model can also cover more area 
and minimize floor space and is ideal for limited size restaurants. The location of the SOKs is determined by customer flow and the design of the store itself. Thus, the best solution for implementing SOKs in limited space stores is by having staff trained and expert in efficiently handling the kiosks' traffic, especially during peak hours. Thus, the staff also can manage to operate the kiosks on time to reduce the waiting lines and improve the efficiency of the SOKs (Koontz and Weilhrich, 2019).

Besides the internal issues, the external issues also entail attention to be solved. External issues usually coming from the surrounding factors such as economic, customer, technology, and market (Wimalaratne, 2017). For SOKs, the operation is performed by the customer, hence customer's acceptance before using the SOKs is vital to ensure the smooth process. Kincaid and Baloglu (2007) insisted that it is challenging for a restaraurant to drive customers' mindsets to adapt to new technologies. Although youth today have higher acceptance levels in using SOKs, older generations appear to respond more to the traditional approach that engages human interaction (Toh, 2018). When designing SOKs, the restaurant owner needs to consider age demographics and type of technology. The previous study related to age and SOKs technology shows a negative correlation between age and preference for self-service, with declining percentages as the age rises (Troxell, 2014). Simultaneously, a study by Knowles and Hanson (2018) reveals that older people oppose new technology out of fear of mistakes and anxiety for their social responsibilities.

Thus, some customers are technophobes where they feel uncomfortable and frustrated in using the technology (Kincaid \& Baloglu, 2007), especially when the technological limitation happened during the process. Technical restriction issues that may occur during the operation, such as poor programming usability, support or maintenance of outdated processes, slowed down client aptitudes, and limited usage of the system, mainly during peak hours, has often pushed the consumer away (Travica, 2008). Any bad encounter, especially related to SOKs, influences the customers' perception of the technologies, thereby dramatically reducing their usage and acceptance (Toh, 2018). SOKs have been introduced in the QSR environment to optimize operational performance, boost speed, increase profitability, improve productivity, and create competitive advantage and not create chaos.

\section{Methodology}

This study applied qualitative research methodology to illustrate contextual understanding with the focus to understand behavior, principles, and beliefs (Bell, Bryman, \& Harley, 2019). The phenomenology research was designed in which the goal was to describe lived experience rather than to explain or quantify it in any way. In this research, data were collected through open ended-interview with targeted informants. This method enables the researcher to gather the required information and describe the issues and challenges in implementing digital ordering kiosks in the QSR in Klang Valley. In other words, it aims to explore the internal and external issues faced by the managerial team in digital dining implementation in the restaurant. The qualitative data collection methods allow the researcher to determine the direction and area exploration that the researcher may not have anticipated.

The sampling technique that has been used in this research was purposive sampling, where it involves informants who have specific criteria and could provide various information on the 
area. The selection of the informants had been made based on several criteria includes; (a) the workers, supervisor, or manager, (b) working in the quick-service restaurant in Klang Valley, (c) someone that encounter or deal with self-ordering kiosk, and (d) understand Malay or English. Six informants from QSR in the Klang Valley area were involved as the sample for this study; three are regular crew, and the remaining are manager, RGM (Restaurant General Manager), and GEL (Guest Experience Leader) of the restaurant. All of the informants have at least four months to three years of working experience at QSR. Klang Valley area is chosen because most QSR outlets already implement the SOKs found in big towns, especially in the Klang Valley. Notably, McDonald's outlet's 42\% market share is recorded in Klang Valley, while SOKs for KFC outlets are only available around the Klang Valley area (Goh, 2019).

The instrument used in this research was the interview questions. Overall, the interview questions were divided into three sections, detailing the required information on the issues and challenges of implementing a quick-service restaurant's digital ordering system. The scheduled interview sessions last between 45 minutes to one hour per session and are digitally recorded through phone and voice recorder once the informants have obtained permission. The interviews were then transcribed verbatim, and the data were analyzed through thematic analysis using Atlas. ti software to code, categorised and themed the data.

\section{Results}

The restaurant industry appears to be growing, and as time goes by, technology has become more critical as it offers a lot of benefits to the business. Industrial revolution 4.0 has led people towards connection, intelligent automation, a smart teamwork where humans and machines interact to accomplish the goal. It also infers that a fresh perspective to adapt to technological advancement is needed for the QSR to improve the service quality (Radziwill, 2018). This research was conducted to explore the management's internal issues and identify the external challenges in SOKs implementation in the QSR environment. The results obtained from the interview transcription that the technology-based SOKs currently are the most advanced technology utilized in the QSR to improve quality and enhance guest experiences.

\section{Internal Issues in Self-Ordering Kiosk (SOKs)}

The first internal issue related to the implementation of SOKs is the employee's staffing. Staffing is a core function of management that defines and supplies the organization with adequate competent and skilled staff at all levels. The management's staffing roles include recruitment, selection, training, development, appraisal, and personnel remuneration. Derived from the finding, the well-educated and trained staff must ensure the staff can be a coach to educate customers when using the SOKs. The staff needs to be ready to serve the customer during the SOKs process happened. So, no doubt, training is vital to ensure that employees can acquire knowledge and equip themselves with the proper skills from experienced mentors especially when associating with new technology (Lam \& Zhang, 2003). This is supported by Mehrotra, Verma, and Chakraborty (2018), where the staff of QSR was trained to provide friendly and pleasant customer service and satisfactory performance. QSR management may have provided a robust and structured training platform to ensure that the staff are knowledgeable to avoid future problems.

"Training is not an issue. [But] staffing, yes. It depends on how long you have been using SOK. We need to educate customers on how to 
use the SOK. Now the main challenge is that the SOK coach (customer teacher) must always be there" (Informant 6)

In addition, another internal issue is the shortage and untrained staff. The restaurant's low staffing level and lack of skilled employees force the team to multitask to offer a better guest experience and achieve the restaurant goal. Sometimes, the staff needs to switch their position in certain circumstances. The different roles of the task required additional skills and due to this, some of the staff cannot cope with the current situation. This is parallel with the previous research, which noted that the high turnover of staff is a common problem in the restaurant industry for a long time (Seebacher, 2017). The staff is forced to multitask, which leads to demotivation, making them decide to quit their job. Thus, the management needs to find strategies and other alternatives besides depending on human skills to fulfill the customers' demands (Wimalaratne, 2017).

"Due to the lack of order taker, the server needs to play this role. He has to change his position". (Informant 6)

Moreover, the staffing issue also occurs with the table service due to SOKs implementation, especially for the restaurants with multi-storey buildings. It seems a challenge for the staffs to fulfill the demand to send the order from the customer to the table within the standard period of time. Thus, it reduces the performance when only selected customer demand can be met with a low staffing level (Slack, et al., 2021). Therefore, restaurants require effective staffing strategies to improve the performance and productivity of the restaurant.

"It is challenging to send the Table Service (sending the food to the customer table). This is two-storey high building. [I think] If it is a one-level store, there is no table service issue." (Informant 6)

Next, most food and beverage operations have limitations with space. By installing SOKs, it can save some space in the restaurant and reduce the waiting line. It aligns with the previous findings where the implementation of SOKs can easily maximize space to fit the restaurant's needs (Eastwood, 2018). Thus, the ordering kiosks do not consume a large area in the restaurant for its installation. However, location matters have become the problem. Informants highlighted that the kiosks' implementation and activity affect the space of the restaurants, especially during the peak hours when the queue traffic becomes congested, and the outlet became crowded. Sometimes, the long queue traffic could cause the main entrance been blocked and bump into the other customer's table. To avoid this problem worsen, it is essential to place the SOKs in strategic places that allow customers to place orders while avoiding consuming space and congestion during peak hours (Eastwood, 2018).

"The store is crowded due to peak hours and also because it is a small space." (Informant 1)

"...The implementation of the SOK took up a lot of space as the restaurant size is quite small." (Informant 2) 
"...Because the installation is in the middle of the store... Sometimes

it collides with another customer's table in the area..." (Informant

4)

\section{External Issues in Self-Ordering Kiosk (SOKs)}

The finding discusses the use of SOKs from the customer perspective and the team managing the technology. The issues pertaining to this system and its application, which are beyond their controls, have been highlighted.

For many years, quality of services has been the subject of comprehensive research in QSR restaurants and significantly affects how customers interact to achieve positive service outcomes. The research related to customers includes acceptance, satisfaction, and loyalty towards products or services offered (Iqbal, Hassan \& Habibah, 2018). The result showed that the rejection of SOKs by some customers was based on the customer perception and acceptance before they could fully adapt to the new technology of SOKs. Customers resisted using the SOKs caused by the technology restriction, including unfamiliarity, long queue, timeconsuming, complex, and difficulty to use. Kincaid and Baloglu (2007) conclude that a restaurant can drive customers' mindset to adopt the new technologies. The inability to encounter SOKs tends to influence the customers' perception of the technologies, thereby dramatically reducing their usage and acceptance (Toh, 2018).

"...customers preferred to order at the counter because some of them didn't know how to order on SOKs." (Informant 1)

"...customers sometimes refused to use SOK because they thought the line was very long and they had to queue... they noted that it is difficult to use, complex and confusing. So, it is easier to go and order through the counter." (Informant 2)

Typically, restaurants used SOKs because they believe that new technology can enhance customer satisfaction and boost operational efficiency. However, there are also barriers in utilizing the technology, which is caused by the system failure. Issues that may happen during the operation include poor programming usability, support or maintenance of outdated processes, slowed down client aptitudes, and limited system usage. In this case, process failure was considered a source of customer dissatisfaction (Dabholkar \& Spaid, 2012; Silva). Therefore, managers need to figure out how to deal with all of these technology restrictions.

"SOKs need an internet connection. Sometimes the PC is jammed and slow to proceed..." (Informant 1)

"When the product item is out of stock, the manager needs to close or make the item unavailable. If there is any delay, it will cause a serious problem." (Informant 2)

According to them, the problems that usually happened with the SOKs are when the customer placed an order on food items and already paid for the food through kiosks; and suddenly, when the time to pick up the order, the food was currently unavailable. According to the 
informants, the system connection or connection line can be 'hanged' or jammed, which may slow down the process and drag the total order time. The issue is also found in the cashless method for SOKs, which must be updated regularly to meet the customer's demand. It is crucial to keep customers satisfied and pleased with the quality, service, and products offered by employees to be competitive in this competitive marketplace (Lam \& Zhang, 2003). The management needs to train and prepared the strategies on how the staff should act if the issues happened.

\section{Conclusion}

This study's primary objectives were to explore the management team's internal issues in SOKs implementation and identify the external challenges in implementing SOKs in QSR. The findings found that the internal issues faced by the management team in SOKs implementation include the employee's staffing and limited space of the restaurant. While customer acceptance and technology restriction are the external challenges of the technology implementation in this industry. It can be concluded that technology has been an excellent tool in the quick-service restaurant but comes with barriers for successful implementation. Thus, the findings on these issues and challenges will undoubtedly benefit the existing and new restaurants and food service industry in improvising and searching for the obstacles they face to improve their service in offering digital dining experience to millennial customers. This study will help the restaurant business effectively understand the issues and challenges in SOKs implementation to enhance guest satisfaction.

\section{Acknowledgement}

The authors wish to thank Universiti Putra Malaysia for the financial support under the Putra Young Initiative Grant (GP-IPM) [Vote no: 9673900].

\section{References}

Appetize Technologies. (2019). A Step-By-Step Guide to implementing Self-Service Kiosks. Retrieved 18 Feb 2020 from Appetize: https://appetize.com/a-step-by-step-guide-toimplementing-self-service-kiosks/

Baba, N., Shahril, M. A., \& Hanafiah, M. H. (2020). Self-Ordering Kiosk Usage and PostPurchase Behaviour In Quick Service. Journal of Tourism, Hospitality \& Culinary Arts (JTHCA), 12 (1). 1-17.

Bell, E., Bryman, A., \& Harley, B. (2019). Business research methods ( $5^{\text {th }}$ ed). Oxford University Press.

Bitner, M. J., Ostrom, A. L., \& Meuter, M. L. (2002). Implementing successful self-service technologies, Academy of Management Executive, 16(4), 96-108.

Chen, C. J., \& Huang, J. W. (2009). Strategic human resource practices and innovation performance - The mediating role of knowledge management capacity, Journal of Business Research, 62(1). 104-114

Cheong, S. N., Chiew, W. W., \& Yap, W. J. (2010). Design and development of Multi-touchable E- $\quad$ restaurant Management System. 2010 International Conference on Science and Social Research (CSSR 2010), Kuala Lumpur, Malaysia. pp. 680- 685. DOI: 10.1109/CSSR.2010.5773867 DOI: 10.1109/CSSR.2010.5773867

Cheong, S. N., Chiew, W. W., \& Yap, W. J. (2010). Design and development of Multi-touchable E-restaurant Management System. International Conference on Science and Social Research (CSSR 2010), IEEE, 680-685. doi: 10.1109/CSSR.2010.5773867 
Considine, E., \& Cormican, K. (2017). The rise of the prosumer: An analysis of self-service technology adoption in a corporate context, International Journal of Information Systems and Project Management, 5(2). 25-39

Dabholkar, P. A., \& Bagozzi, R. P. (2002). An Attitudinal Model of Technology-Based SelfService: Moderating Effects of Consumer Traits and Situational Factors. Journal of the Academy of Marketing Science, 30(3), 184-201. DOI: https://doi.org/10.1177/0092070302303001

Dabholkar, P. A., \& Spaid. B. I. (2012). Service failure and recovery in using technology-based self- service: effects on user attributions and satisfaction, The Service Industries Journal, 32(9). 1415- 1432, DOI: 10.1080/02642069.2011.600518

Doub, A., Levin, A., Heath, C. E., \& LeVangie, K. (2015). Mobile appetite: Consumer attitudes towards and use of mobile technology in the context of eating behaviour. Journal of Direct Data Digit Mark Practice. 17: 114. DOI:

https://doi.org/10.1057/dddmp.2015.44 https://doi.org/10.1057/dddmp.2015.44

Eastwood, M. (2018). Reasons why your restaurant needs self-service kiosk. Retrieved 25 July 2020 from Modern Restaurant Management:

https://modernrestaurantmanagement.com/reasons-why-your-restaurant-needsself-service-kiosks/

Geissbauer, R., Vedso, J., \& Schrauf, S. (2016). Global Industry 4.0 Survey: Building the digital enterprise,

Goh, S. (2019). Self-service kiosks (SOKs) are being introduced by KFC in Klang Valley. TallyPress. https://tallypress.com/fun/self-service-kiosks-soks-are-being-introducedby-kfc-in-klang-valley/

Hapner, B. (2019). What You Know About Self Ordering Software. Retrieved 27 Nov 2019, from Fast Casual: https://www.fastcasual.com/blogs/what-you-need-to-knowabout-kiosk-self-ordering software/

Hopper, G. (2018). Futuristic feeds: The best digital dining experiences. Suitcase Magazine Ltd. https://suitcasemag.com/travel/explore/digital-dining-experiences/

Iqbal, M. S., Hassan, M. U., \& Habibah, U. (2018). Impact of self-service technology (SST) service quality on customer loyalty and behavioral intention: The mediating role of customer satisfaction, Cogent Business \& Management, 5(1), 1-23. DOI: 10.1080/23311975.2018.1423770

Ivanov, S., Webster, C., \& Berezina, K. (2017). Adoption of robots and service automation by tourism and hospitality companies. Revista Turismo \& Desenvolvimento, 27, 15011517.

Justin. (2017). Pizza Hut Malaysia debuts first digital concept store and robot waiters. Hype. https://hype.my/2017/147153/worldwar2-bomb-exploded-mrt-construction-site/

Kasavana, M. L. (2008). Convergence of Self-Service Technology. Hospitality Upgrade Magazine, Spring 2008. 124-128.

Kelso, A. (2019). Self-Order Kiosks Are Finally Having A Moment in The Fast-Food Space. Forbes. https://www.forbes.com/sites/aliciakelso/2019/07/30/self-order-kiosks-arefinally-having-a-moment-in-the-fast-food-space/?sh=2fdc20024275

Kincaid, C. S., \& Baloglu, S. (2007). An empirical investigation of attitude toward self-service technology (SST) in quick service restaurants. Unpublished conference paper.

Knowles, B., \& Hanson, B. L. (2018). The wisdom of older technology (non)users. Communication of ACM, 61(3), 72-77. DOI:https://doi.org/10.1145/3179995 
Kokkinou, A., \& Cranage, D. (2013). Using self-service technology to reduce customer waiting times. International Journal of Hospitality Management, $33.435-445$. https://doi.org/10.1016/j.ijhm.2012.11.003

Kolberg, D., Knobloch, J., \& Zuhlke, D. (2017). Towards a lean automation interface for workstations, International Journal of Production Research, 55(10), 2845-2856. https://doi.org/10.1080/00207543.2016.1223384

Koontz, H., \& Weihrich, H. (2019). Essentials of management: An international, innovation and leadership perspective (11th ed.). McGraw Hill India.

KPMG. (2019). Customer first customer obsessed: Global customer experience excellence report, 2019. KPMG International Cooperative.

https://assets.kpmg/content/dam/kpmg/it/pdf/2020/01/Global-customerexperience-excellence-2019.pdf

Lam, T., \& Zhang, H. Q. (2003). Job satisfaction and organizational commitment in the Hong Kong fast food industry, International Journal of Contemporary Hospitality management, 15(4), 214-220. https://doi.org/10.1108/09596110310475667

Liebman, T. S. (2003). Automated self-service ordering system and method of use. International Patent Classification.

Mason, K., Jones, S., Benefield, M., \& Walton, J. (2013). Consumer Perceptions of Quick Service Restaurants. Journal of International Business and Economics. 13. 109-116. DOI: $10.18374 / J I B E-\quad 13-4.8$.

Mehrotra, S., Verma, S., \& Chakraborty, I. (2018). Samosa Singh: The fast food of India. Emerald Emerging markets case Studies, 8(3), 1-32.

Meuter, M. L., Ostrom, A. L., Roundtree, R. I., and Bitner, M. J. (2000). Self-service technologies: Understanding customer satisfaction with technology-based service encounters. Journal of Marketing, 64(3): 50-64.

Mexen, C. (2015). Perceived factors influencing the acceptance and adoption of self-service technology. [Unpublished Master dissertation]. Universiti Tunku Abdul Rahman.

Neiman, H. (2019). Why are self-order kiosks on a roll in US markets? Retrieved 17 Mac 2020 from Kiosk Marketplace: https://www.kioskmarketplace.com/blogs/why-are-selforder-kiosks-on-a- roll-in- us-restaurants/

Nicola, J. (2019). Digital transformation sweeps over restaurant industry. QSR Magazine. https://www.qsrmagazine.com/outside-insights/digital-transformation-sweeps-overrestaurant-industry

Nokman, F. S. (2017). McDonald's Malaysia targets 450 more restaurants by 2025. Retrieved 25 July 2020 from News Strait Times: https://www.nst.com.my/business/2017/12/312250/mcdonalds- malaysia-targets450-more-restaurants-2025

Ottenbacher, M., \& Gnoth, J. (2005). How to develop successful hospitality innovation. Cornell Hotel and Restaurant Administration Quarterly, 46(2) 205-22. DOI: 10.1177/0010880404271097

Pantelidis, I. S. (2009) High Tech Foodservice; an overview of technological advancements. CHME 18th Annual Research Conference, Eastbourne, UK.

Parso, H. G., \& Khan, M. A. (1992). Trends in the Quick Service Restaurant Industry. Hospitality Review, 10(1). https://digitalcommons.fiu.edu/hospitalityreview/vol10/iss1/3

Prasad, M., Scornavacca, E., and Lehmann, H. (2005). Using wireless personal digital assistants in a restaurant: Impact and perceived benefits. 69- 74 . DOI: 10.1109/ICMB.2005.112. 
Radziwill, N. (2018). Let's Get Digital: The many ways the fourth industrial revolution is reshaping the way we think about quality. Quality Progress, 24-29. Retrieved 25 July 2020 from: https://arxiv.org/ftp/arxiv/papers/1810/1810.07829.pdf

Rajput, S., \& Singh, S. P. (2019). Connecting circular economy and industry 4.0. International Journal of Information Management, 49, 98-113. https://doi.org/10.1016/j.ijinfomgt.2019.03.002

Ramos, Y., \& Castro, A. (2017). Point-of-sales system in food and beverage industry: Efficient technology and it user acceptance, Journal of Information Science and Computing Technologies, 6(1), 582-591. http://scitecresearch.com/journals/index.php/jisct/article/view/1024

Rastegar, N. (2018). Adoption of Self-service Kiosks in Quick-service Restaurants. [Unpublished Master's dissertation]. The University of Guelph, Ontario, Canada.

Ravenel, J. P., Chong, T., \& Silva, J. (2016). System and Method of Providing Digital Media Management in A Quick Service Restaurant Environment. U.S. Patent No.: 9,444,932. San Diego, CA (US). Tillster, Inc.

Samantha, R. L., Ganewatta, G. K. H., \& Åmo, B. W. (2011). Challenges faced by SMEs in developing countries adopting ICT: A case study from the hotel industry in Sri Lanka. In Åmo, B. W. (Ed.), Conditions for entrepreneurship in Sri Lanka: A Handbook, (99-113), Shaker Verlag.

Schwab, K. (2016). The 4th Industrial Revolution: What It Means, How to Respond, Retrieved 29 Dec 2019 from World economic forum:

https://www.weforum.org/agenda/2016/01/the-fourth-industrial-revolution-what-itmeans-and-how-to-respond/

Seebacher, N. (2017). How Digital Is Changing Appetites for Restaurant Experiences. Retrieved 29 Dec 2019 from cmswire.com: https://www.cmswire.com/digital-experience/howdigital-is-changing- appetites-for-restaurant-experiences/

Slack, N. J., Singh, G., Ali, J., Lata, R., Mudaliar, K., \& Swammy, Y. (2021). Influence of fast food restaurant service quality and its dimensions on customer perceived value, satisfaction and behavioral intentions, British Food Journal, 123(4), 1324-1344. https://doi.org/10.1108/BFJ-09-2020-0771

Statista Research Department. (2021). Malaysia - visited fast food restaurants 2018. https://www.statista.com/statistics/561040/Malaysia-visited-fast-food-restaurants/

Tillster. (2020). Self-service kiosk industry: Continued growth and advancements across restaurant industry. https://www.tillster.com/blog/2020/3/26/self-service-kioskindustry-continued-growth-and-advancements-across-restaurant-industry

Toh, M. H. (2018). Lifting productivity in Singapore's retail and food services sectors: The role of technology, manpower and marketing. World Scientific Publishing Company Pte Ltd.

Travica, B. (2008). Influence of information culture on adoption of a self-service system, Journal of Information, Information Technology and Organizations, 3, 1-15.

Troxell, N. (2014). What to consider when implementing restaurant kiosks. Retrieved 20 Jan 2020 from Qsrweb.com: https://www.qsrweb.com/articles/what-to-consider-whenimplementing-a-restaurant-kiosk/

Wimalaratne, S. (2017). How technology is shaping the fast-food industry. Retrieved 30 Dec 2019, from cambridgeconsultants.com:

https://www.cambridgeconsultants.com/insights/opinion/how- technologyshaping-fast-food-industry 
Ying, T. L. (2016). Fast food Consumption Behaviour Among Generation $Y$ in Malaysia. [Unpublished Master Thesis]. Universiti Tunku Abdul Rahman, Malaysia.

Zolkafli, N. F., Nizam, F. N., Haslam, N. A. A., \& En, W. Y. (2016). Factors influencing customers' acceptance toward self-service kiosks in Northern Peninsular Malaysia. Universiti Malaysia Kelantan, Malaysia. 